\title{
Effect of Educational Nursing program on reducing the incidence of Venous Thromboembolism among postpartum women.
}

\author{
Entisar M. Youness1, Shaimaa G.Hassen1, Hanan M.Youness 2\& Sahra \\ Z.Azer3 \\ Obstetrics \& Gynecological Nursing Department, Faculty of Nursing, Assiut University1,Medical surgical \\ Nursing Department. Faculty of Nursing, Cairo University 2, Adult (Medical surgical) Nursing Department, \\ Faculty of Nursing, Assiut University3,Egypt.
}

\begin{abstract}
Background: Venous thromboembolism (VTE), which includes deep vein thrombosis (DVT) and pulmonary embolism (PE), is a serious cause of direct maternal morbidity and mortality in hospitals, that is highly preventable. Literatures strongly support patient education on VTE prevention as it can promote strategies such as early ambulation and encourages self assessment and self reporting of VTE signs and symptoms. Aim of this study was to assess the effect of educational nursing program on reducing the incidence of VTE among postpartum women at Assiut Women's Health Hospital, postpartum unit and followed up at post partum outpatient clinic.

Subjects and Methods: A randomized controlled trial study design used and 400 immediate post partum women were divided randomly into two main groups, intervention and control groups. Intervention group received an educational nursing program about VTE, while the control group received the routine post partum hospital care.

Results: Number of new cases of post partum VTE that occurred among women who received the educational program about VTE prevention were significantly lower than those who received the routine hospital post partum care. Women's knowledge about VTE were significantly improved after implementing the educational program.

Conclusions: Findings of this study proved that postpartum women could benefit from the educational nursing program about VTE and this appeared in the occurrence of only one DVT case of the intervention group VS two DVT cases and one pulmonary embolism case among the control group.

Recommendations: This study highlights the need to strengthen the nurses' role in providing patient education about VTE and indicates the need to improve resources that support obstetric nurses in educating their post partum women about VTE.
\end{abstract}

Keywords: Deep Venous Thrombosis; Pulmonary embolism; Postpartum period;

\section{Introduction}

Post partum associated venous thromboembolism(VTE), which may manifest as pulmonary embolism(PE) or deep vein thrombosis (DVT), is an important cause of maternal morbidity (Alonso.et.al, 2012). Pulmonary embolism remains the leading cause of mortality in developed countries, accounting for approximately $30 \%$ of all maternal deaths(Lewis, 2007). Every year, an estimated incidence of 10.6 per 100.000 of Americans will suffer from deep- vein thrombosis and pulmonary embolism(Official American Thoracic Society,2011).Risk is highest during the postpartum period. In Egypt the estimated incidence is 1 every 5.000 pregnant women suffer from VTE every year (EDHS,2014). Possible sites are Pulmonary embolism and Deep vein thrombosis ( Elizabeth,2013).

Deep- vein thrombosis and PE are collectively known as venous thromboembolism(VTE). Deep- vein thrombosis is a common but under- diagnosed medical condition that occurs when a thrombus (blood clot) forms in one of the large veins, usually in lower limbs, leading to either partially or completely blocked circulation. The condition may result in health complications, such as PE, if not diagnosed and treated in a timely and effective manner. Pulmonary embolism can occur when a fragment of blood clot breaks loose from the wall of the vein and migrates through the heart to the lungs. When that clot is large enough to completely block one or more of the vessels that supply the lungs with blood, it can result in sudden death( Greer,2012).

The relative risk of antenatal VTE is approximately 5 -fold higher in pregnant women than in nonpregnant women of the same age due to the changes in the coagulation and venous systems associated with pregnancy, but the absolute risk remains low at around 1 in 1000 pregnancies (Bates et, al. 2012). Events are spread across the 3 trimesters, with more than $50 \%$ of events occurring in the first 20 weeks of pregnancy. The puerperium is the time of greatest risk, with estimates of relative risk of approximately 20 -fold. Approximately $80 \%$ of events occur in the first 3 weeks after delivery likely because of the addition of trauma to the pelvic 
vessels in the course of delivery causing endothelial damage compared with the non-pregnant woman, in whom distal DVT is more common, most events in pregnancy are ileofemoral and left sided (Jacobsen et al. 2008). Pregnant women are prone to forming blood clots, leading to an increased risk of developing DVT, pulmonary embolism, or thrombosis at other more rare sites which can be caused by hormonal changes and pressure on the veins by the uterus. The increased VTE risk requires special attention in pregnant woman. The haemostatic system changes from the second trimester in order to prepare for the haemostatic challenge of delivery (Yaakobche et al, 2010).

Despite increased awareness of the risks of VTE and use of prophylaxis, deep vein thrombosis and pulmonary embolism comprising different manifestations of the same clinical entity referred to as venous thromboembolism, are a significant cause of morbidity and mortality. Despite pulmonary embolism being considered the most preventable cause of in-hospital death, the use of appropriate thromboprophylaxis remains suboptimal in many patients. With DVT, pain or swelling of the leg (particularly the left leg) are the common presenting complaints. Other features include tenderness, increased temperature, lower abdominal pain or a raised white cell count (Hodgson \& Emed, 2007).

The key to prevention, as with diagnosis, is the awareness of the condition. Recent reports of the UK Confidential Enquiries into Maternal Deaths have raised awareness of thromboembolism and especially of risk factors (Pomp et al. 2008). Patient education on VTE has not been sufficiently addressed, according to some recent studies. An American national survey reported that $74 \%$ of adults have negligible knowledge of DVT and its effects on health. Studies of women in the postpartum period and cancer patients reached similar conclusions(Noble, 2006).

Addressing patients' knowledge of VTE prevention during a hospital stay can promote patient involvement in safety by encouraging participation in recommended activities such as early mobilization and calf-pumping exercises. Increased patient knowledge also promotes adherence to pharmacological thromboprophylaxis, as one nursing study reported that patients who did not understand the purpose of their medications occasionally refused the anticoagulant injections (Hodgson \& Emed, 2007). Knowledge of VTE also allows patients to self assess and self report VTE symptoms not only while in the hospital but also after discharge, enabling patients to obtain timely medical assistance (Kehl-Pruett, 2006). This is especially important for today's trends of shorter hospital stays (Morrison, 2006) and (Goldhaber ,2007).

Nurses can positively affect outcomes in mechanical or physical DVT prophylaxis simply by educating patients regarding the importance of physical therapy and early movement through early ambulation, leg elevation, leg flexing, active and passive range of motion exercises (Davis,2004). They are also being on the frontline of thrombosis prevention, by playing an essential role in diagnosis and risk assessment, applying timely preventive methods and providing vital educational and psychological support for patients with venous thromboembolism, so skilled nursing intervention can be lifesaving (Tooher, et.al, 2010).

\section{Aim of The Study}

The aim of the present study was to assess the effect of educational nursing program on reducing the incidence of Venous Thromboembolism among postpartum women.

The specific research questions addressed in this study were:

1. To what extent are women have knowledge and awareness of VTE, signs and symptoms and mechanical thrombo-prophylaxis measures?

2. To what extent is the effect of educational program on reducing the incidence of VTE?

\section{Subjects And Methods}

3.1.Research Design: This study was a randomized controlled trial that was conducted to compare the outcome results of receiving the educational nursing program about prevention of VTE, (Intervention group) versus the routine hospital care (control group).

3.2.Setting: The study was conducted at the postpartum ward of Obstetrics \& Gynecology Department, Women's Health Hospital, Assiut University, Egypt, during the period from the first of January, 2015 to the end of August, 2015.

3.3.Sample size: Sample size calculation was based on the primary outcome measures by using two sided chisquare $(\chi 2)$ test with $\alpha$ of 0.05 , a total sample size of at least 400 women divided into 2 groups (200 for each arm) with $95 \%$ power to detect a $10 \%$ difference in the proportion of the educational nursing program assuming failure to follow up rate of $10 \%$ (Epi-info $^{\text {TM }}$, CDC, USA, 2008).

3.4.Subjects: A selected sample of 400 postpartum women were recruited for this study. Women who had immediately delivered vaginally or abdominally were invited to participate in the study prior to discharge from 
the hospital. Considering the mobility patterns of today's population, researchers anticipated that about $10 \%$ of participants would be lost to follow-up, additional 40 cases was included in the study to restore any case lost from the follow up phase. All the included women were randomly assigned into two main groups, 200 women in each.

Group 1: Intervention group who received the educational nursing program about VTE prevention.

Group 2: Control group who received the routine hospital care.

3.5.Randomization: Randomization was done by using computer-generated random tables and concealed serially-numbered closed opaque envelopes . After acceptance of eligible women to participate in the study, they were assigned randomly to either one of the two groups. Once allocation has been done, it could not be changed.

3.6.Exclusion criteria: Women who refused to participate in the study, anticipation of difficulty of subsequent communication with the woman and un-availability of phone number to contact with the woman.

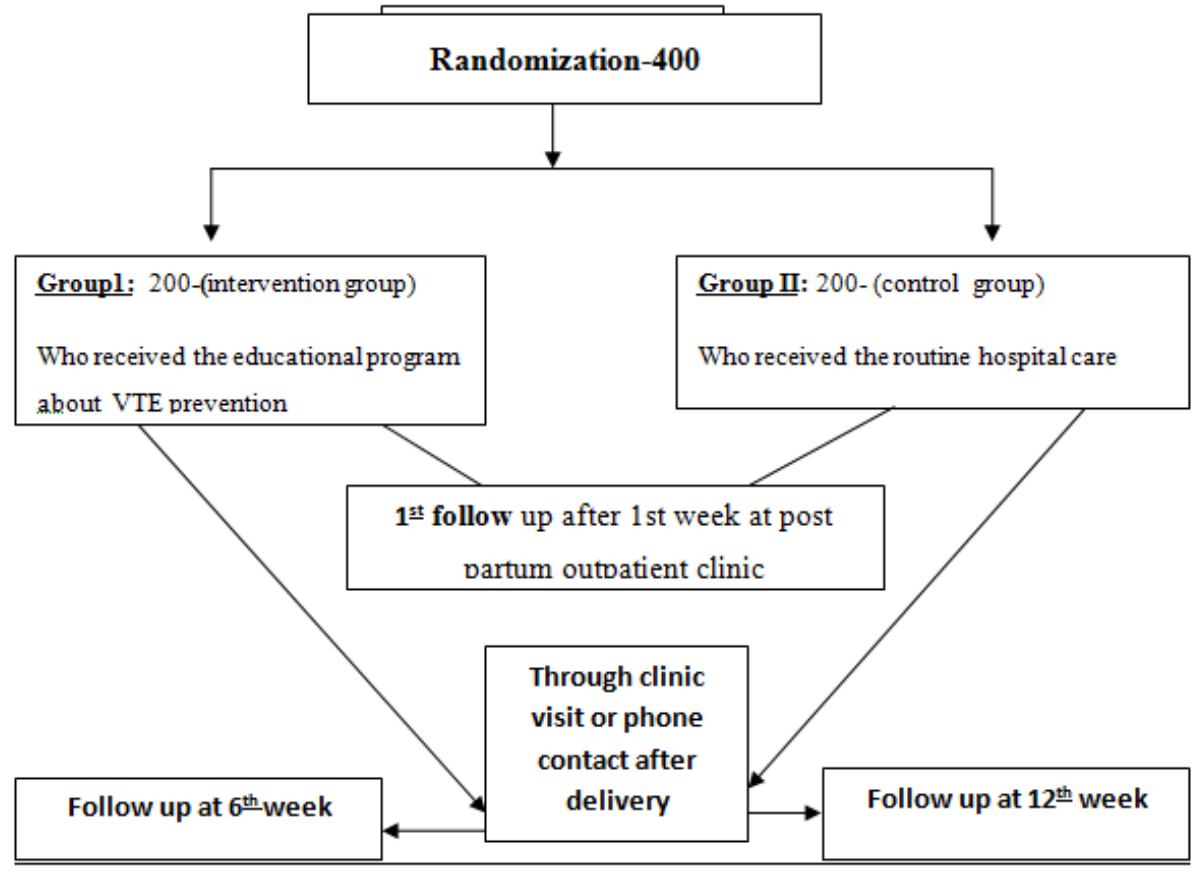

Figure(1) study flowchart shows the study profile of women and the randomization process of the groups.

\subsection{Tools of the study:}

Data were collected using an interview questionnaire that was designed by the researchers and validated to collect the necessary data. It based on review of related literature and reviewed by panel of experts from Obstetrics and Gynecological nursing and medical related specialists. The questionnaire was compromised of three parts. The first part was designed to investigate women's of both groups regarding demographic characteristics age, educational status and occupation. It also included parity status and obstetric history. The second part was planned to determine the current obstetrical and medical history. Current pregnancy status, presence of medical diseases as well as specific details about their past venous thromboembolic events (including occurrence of PE or DVT), presence or absence of precipitating risk factors prior to their event, presence of clinical risk factors such as prolonged immobility and obesity, family history of VTE, type of treatment for their event(s), completeness of their recovery (for example, presence or absence of residual chest pain or shortness of breath, and/or residual leg swelling, pain or discoloration), and the presence or absence of prior experience with injection of prophylactic doses of LMWH during pregnancy.

It also contained history of receiving thrombo-prophylactic whether it was pharmacologic agents or non pharmacologic. This part included women's knowledge about VTE signs and symptoms, knowledge about measures that may help in prevention of VTE. The third part is the part of follow-up which included reminding the women at least once a week by telephone to practice leg exercise and follow the preventive measures, data about the presence of any signs and symptoms related to DVT or PE with emphasizing on the necessity to visit the post partum outpatient clinic at least at the end of first week, 6-week and after 12-weeks postpartum. This part addressed the effect of performing leg exercises and following the nursing instructions on the occurrence of VTE. 


\subsection{Pilot Study:}

A pilot study was conducted on $10 \%$ of women of both groups (40 post partum women) from the Women's Health Hospital, Assiut University Hospitals, to test feasibility of tools and time required to be applied. Simple modification was done of some items of the questionnaire that they were not consistent with this study. The participants of the pilot study were included in the study sample.

\subsection{Content Validity:}

To establish face validity, the questionnaire was piloted on panel of 5 experts of two Obstetrics and Gynecological Nursing staffs and two Obstetrics and Gynecological Medicine staffs and one Hematology Medical staff. They reviewed the instruments for clarity, relevance, comprehensiveness, understanding, applicability and easiness.

\section{Administrative Design}

Before the conduction of the pilot study as well as the actual study, an official permission and consent were obtained from the dean of the Faculty of Nursing, as well as the Director of Women's Health Hospital, Assiut University Hospitals.

\subsection{Procedure:}

An approval of the Ethical Review Board of the Assiut Medical School and Faculty of Nursing was obtained. A written consent was obtained from all participants after reading the patient information sheet or having it read for them if not able to read or write. Researchers met with women who expressed an interest in participation, and explained the purpose of the study and carried out the informed consent process and filled the data of the questionnaire from each woman. Before conducting the nursing program the investigators assess the women's knowledge regarding VTE. After that, the investigators emphasized on the importance of providing greater information and education for women to improve awareness of VTE through giving them instructions immediately after delivery to be followed as physical prophylactic simply by educating physical therapy and early movement (e.g., immediate ambulation after delivery and get up and walk around every 20 minutes, leg elevation, foot flexing, active and passive range of motion exercises, if she has to sit for a long time, stretch legs and feet every 20 minutes). Drink plenty of fluids as water, and the use of sequential compression devices in high risk cases to prevent blood clotting. Pharmaceutical prophylaxis including the use of blood thinning (anticoagulant) drugs as prescribed by the physicians. Each participant was allocated to the proper group according to the study profile. The interview took about 25-30 minutes with each woman in both groups and another 30 minutes for educating them about the preventive measures and exercises of VTE . Data collection took place within 6 months from first of January, 2015to the end of follow up at August, 2015.

A pamphlet containing what women need to know about VTE prevention provided by pictures of leg exercises was given to each woman. It was explained to the intervention group in a very understood speech and written in a very simple clear Arabic language. The Educational Nursing Program included (What is DVT and PE, the connection between VTE, pregnancy and post partum weeks afterward, risk factors, symptoms, measures that can prevent it, time of seeking medical help and finally the place of referral if any signs or symptom arised).

\subsection{Follow up Phase:}

The researchers followed- up these women of the intervention group and motivated them to perform the exercises through telephone calls by reminding the women with the benefits of exercises and motivating them to perform exercises every day at regular times to avoid forgetting it and make exercise a habit. For both groups, ensuring that all the participants women came to the postpartum outpatient, evaluating the presence of any signs and symptoms at the end of first week, after 6 weeks and at the end of the 12- week postpartum at the post partum outpatient clinic. Proper referral to the vascular outpatient clinic was done by the help of the attendant obstetricians and the hospital policy for women who had any suspicious complains indicating VTE symptoms.

\subsection{Expected outcome:}

The primary research outcome for this study was reducing the incidence of VTE in intervention group. Secondary outcome included increased women's knowledge about VTE and following the nursing instructions about the preventive measures of VTE.

4.4.Ethical considerations: Confidentiality was maintained, no health hazards affected the women, data is only available to the researchers and the participants. The consent form included a section that participants accepted to receive a phone call from the researchers to follow up them and to complete the interview. The safety of the 
educational nursing program on their health was explained. Women who refused to participate were not in any way affected by the quality of services they received in hospital.

4.5.Statistical Analysis: Collected data were coded and analyzed. Descriptive statistics for the variables were calculated. Variables were compared using chi-square test. Variables were significant at $\mathrm{P}$ value $<0.05$. All the statistical analysis was performed using SPSS package version 16.

\section{Results}

Socio-demographic characteristics of the studied women are summarized in table(1). No significant difference was observed among women of both groups regarding their age, education occupation and their residence areas. Regarding the level of education, more than one third of the sample were illiterate $(33.5 \% \mathrm{vs}$ $35.5 \%)$ of the intervention and control groups respectively. Most of the studied women were housewives $(74.0 \%$ vs. $76.0 \%)$ and came from rural areas (83.0\%vs.84.0\%) of the intervention and control groups respectively with no statistical significant difference.

Table (2) shows the obstetrical history of the studied women. It illustrates that about two thirds of the women of both groups delivered more than three times (53.5.0\% vs. $24.0 \%)$ respectively with a highly statistical significant difference between groups, $\mathrm{P}=0.000$. Nearly half of the studied women $(42.0 \%$ vs. $45.5 \%)$ of the intervention and control groups had caesarean delivery. More than two thirds of the studied women in both groups had previous history of using hormonal methods of contraception, and those who using it more than 5 years represents $9.7 \%$ vs. $7.9 \%$, with no statistical significant difference between both groups.

Table(3) illustrates the distribution of the women according to their current obstetrical and medical history. Regarding parity, it is obvious that about two thirds of the studied women in both groups are multiparas and most of them has no medical conditions during pregnancy. Regarding the type of thromboembolic events 2 women reported previous events of DVT in the intervention group vs.3women in the control group and those who received thromboembolic prophylaxis treatments were 27 women among the intervention group vs. 24 women of the control group.

Regarding risk factors which might increase the occurrence of post partum VTE, Table (4) shows that the highest risk factor among the studied women was caesarean section followed by age more than 35 years old and prolonged immobilization. More than one risk factor was found among women of both groups with no statistical significant difference between groups.

Data in Table (5) illustrates the distribution of the studied women according to their knowledge about VTE among groups. Knowledge was varied among women, it was observed that low percentages of women had knowledge about VTE before application of the nursing program while the level of knowledge was significantly increased after the program. Women's knowledge about VTE includes their awareness by things which might increase their chances of getting a DVT, signs and symptoms of DVT, measures would help prevent a DVT, signs and symptoms of PE. More than one response allowed by the women to be checked. Regarding the studied women knowledge about venous thromboembolism, figure (2) illustrates that, adequate knowledge percentage during the pre test was $(8.0 \%)$ and improved to $(87.0 \%)$ after implementation of the educational program with a highly statistical significant difference $\mathrm{P}=0.000$.

As regards the women's source of knowledge about VTE, Table (6) shows that nurses are the first source of knowledge in $(38.0 \%)$ of women, followed by the physicians in $(29.5 \%)$ of women. New onset of DVT and PE are presented in Table (7) and Figure(3). They highlight the effect of educational nursing program on the occurrence of VTE. They show that there are one new case of DVT among the intervention group vs. 3 cases of the control group, 2 cases DVT and 1 case PE, with a highly statistical significant difference between $\operatorname{groups}(\mathrm{P}=0.000)$.

\section{Case Report:}

The only one case of PE was on her 32 years old, this is the third gravida for her, had three girls including the current delivery. During pregnancy she had pre-eclamptic toxemia and delivered by cesarean section and had recovered normally after delivery. She died after 27 days postpartum with a sudden attack of severe chest pain at home and that attack of pain not exceed half an hour and died before transferring her to the hospital. These data was obtained by the researcher through the telephone call with her family member during the follow up phase. It is really family crises.

\section{Discussion}

Deep-vein thrombosis is preventable, said Bruce Evatt; M.D., Chief of the Hematologic Diseases branch at the CDC " We can reduce the risk of its serious and threatening complications if we raise education and awareness among public and urge all health care providers to institute standards preventive measures "( Samuel,2003). 
The current study aim was to assess the effect of educational nursing program on reducing the incidence of VTE among post partum women. This study compromised 400 postpartum women who delivered vaginally or abdominally, divided into two main groups , the intervention and the control group. It was conducted at Assiut University Women's Health Hospital, Egypt. Personal, labor and delivery characteristics of women who were recruited in this study were compared and no significant differences was found.

Few previously published studies have addressed the effect of non-pharmacological and physical measures that help prevent VTE in pregnant and puerperal women as well as non pregnant women. So it is beneficial to conduct such study in our setting.There are few evidence-based recommendations for the use of non-pharmacological measures in patients to reduce the occurrence of DVT and PE. Usual advice for local care includes limb elevation and local application of heat. Activity should be minimal for several days (i.e., the patient's activity should be limited to walking to the bathroom and kitchen). Graded elastic compression stocking have been indicated only for those had obvious risk factors( Dino and Kenneth,2004 and NelsonPiercy,2011)

Addressing women's knowledge of VTE prevention during a hospital stay can promote their involvement in safety by encouraging participation in the recommended activities such as early mobilization and leg exercises. Increased women's knowledge also promotes adherence to the non-pharmacological thromboprophylaxis as it allows postpartum women to self assessment and self reporting of VTE symptoms not only while in hospital stay but also after discharge and enabling them to obtain timely medical assistance. This is especially important for today's trend of shorter hospital stays.

Study findings demonstrated inadequate level of knowledge of VTE among participants of the intervention group during the pretest phase. This level of knowledge was significantly improved after the implementation of the educational program, from $(8.0 \%$ to $87.0 \%)$. When asked the participant about the VTE knowledge, responses to knowledge items were more varied, and many participants answered that they never received information before about signs and symptoms, chances of getting DVT, how to prevent DVT, and signs and symptoms of PE.

In response to being asked about knowledge related to the measures or risk factors which might increase women's chance of getting DVT, about one third of participants stated they know that immobility and obesity increase the chance of getting DVT and about one quarter of them answered surgery and pueriperium. As regards signs and symptoms of DVT, minority of participants answered swelling in one leg. It was surprisingly that when asked women about signs and symptoms of PE, most of them didn't know any of the signs and symptoms of PE. This lower awareness of VTE is of particular concern because it is a potentially life threatening and can lead to long term complications and cause a significant impact on patient quality of life and health care costs. Participants who had heard of DVT or PE were asked to report how they learned about the conditions. Researchers found that the most commonly reported source of knowledge was the nurses and less frequently from their physicians followed by pamphlets and posters.

These results were inconsistent with the results which was done by sag et al., 2008 who investigated patient's awareness and knowledge of thrombo-prophylaxis as well as patient's satisfaction with the thromboprophylaxis in Canada; they found that majority of hospitalized patients were aware that receiving injections is being to prevent blood clots and reported hearing of either DVT,PE or both conditions. Of the participants who had heard of DVT and /or PE, most of them know immobility was a risk factor but had limited knowledge of symptoms and prevention modalities. Participants of their study reported hearing about VTE more frequently from friends, families or media than from health care providers including nurses. Participants were satisfied with pharmacological thrombo-prophylaxis but were less satisfied with information received. Differences of these results with the current study were owing to the difference of studied patients or the difference of patient kinds that their study were done among hospitalized patient not post partum women.

When analyzing the risk factors compared with that reported in other studies, the current study researchers found that their studied women had similar risk factors with that of Milagros et al.,2011. Their women had risk factors for VTE as age over 35 years, obesity, emergency cesarean section, hypertension, preterm delivery and vaginal bleeding. Deep vein thrombosis (DVT) is a serious problem in the antenatal and postpartum period of pregnancy. Thromboembolic complications are the leading cause of both maternal and fetal morbidity and mortality (Pomp, et al., 2008) The incidence of venous thromboembolism during normal pregnancy is six-fold higher than in general female population of childbearing age ( Iroi et al,2010).

Findings of this study refers to the effect of the nursing educational program on incidence of VTE among post partum women. It presented that the intervention group who received the educational program and followed the nursing instructions had only one case of DVT out of 200, while the control group had a new onset of three cases of VTE out of 200, two DVT and one case of PE a highly statistical significant difference between both groups. These women were diagnosed by DVT after phone call and invited to the hospital to be examined. The obstetricians referred these women to the vascular outpatient clinic. They were investigated by the physicians and objective tests were performed and confirmed by a serial impedance plethysmography, 
ultrasound or contrast venography. The PE case was known through the telephone call during the follow up phase with the family and the investigators after her death. She died within half an hour at the 27 th day after delivery and before transferring her to the hospital by a sudden onset of severe chest pain at home and diagnosed as PE by the ambulance team. It became clear from this study that the participants women had benefits from receiving the basic preventive information. The present study results are likely to be valid, because of the random assignment to the two studied groups. Providing information about VTE to post partum women helped increased compliance and allowed them to participate in their plans of care, particularly with self assessment of risk. Through anecdotal observation of women responses to education that the researchers nurses provided, it was noted that when women understood why they were being asked to practice the exercises as a preventive measures, the immediate postpartum mobilization and being asked to wear compression stocking or take anticoagulant blood agent as prescribed by their physicians, most were much welling to follow the program regimen. These results are different or inconsistent with that of Kearon et.al., 2012 who addressed the incidence and additional risk factors from a London perinatal data base of VTE in pregnancy and puerperium. They reported that, the crude incidence rate of VTE in pregnancy or the puerperium was 85/100.000 maternities. This indicates that if they working in a unit with 5.000 deliveries per year, then four cases per year of pregnancy related VTE would be expected. They interpreted the low incidence in their study because the nature of data base was such the post natal were collected during the period prior to discharge from the hospital. Therefore, postnatal events would be under reported as those occurring after discharge from hospital would not be recorded. It has been estimated that $38 \%$ of puerperal deep vein thrombosis and $22 \%$ of puerperal pulmonary embolism manifest after discharge from hospital. Specialists hospital to which women with cardiac problems would be referred did not contribute and thus these women would be under- represented on the database. Given the association between cardiac diseases and postpartum venous thromboembolism demonstrated in their study, it is reasonable to assume that the incidence or rates of VTE estimated may be slightly lower than in the general UK pregnant population.

\section{Conclusion}

Findings of this study proved that postpartum women could benefit from the educational nursing program about VTE and this appeared in the occurrence of only one DVT case of the intervention group VS two DVT cases and one pulmonary embolism case among the control group.

\section{Recommendations}

Findings suggest that patients require further information on VTE during their hospitalization to enhance their involvement in VTE prevention and recognition, and that the provision of written, patient-directed information could begin to address that lack of involvement. This study highlights the need to strengthen the nurses' role in providing patient education about VTE and indicates the need to improve resources that support obstetric nurses in educating their post partum women about VTE.

\section{Acknowledgement}

Researchers would like to acknowledge the help of all women participating in this study for their valuable participation.:

\section{Results:}

Table(1): Socio-demographic characteristics of the studied women

\begin{tabular}{|c|c|c|c|}
\hline Item & Intervention Group (200) & $\begin{array}{r}\text { Control Group } \\
(\mathbf{2 0 0})\end{array}$ & P-value \\
\hline $\begin{array}{l}\text { Age (years): } \\
\text { Mean } \pm \text { SD }\end{array}$ & $26.44+5.59$ & $25.90+5.63$ & 0.338 \\
\hline -Education: & & & \multirow{7}{*}{0.988} \\
\hline Illiterate. & $67(33.5 \%)$ & $71(35.5 \%)$ & \\
\hline Read \& write. & $57(28.5 \%)$ & $56(28.0 \%)$ & \\
\hline Basic education. & $5(2.5 \%)$ & $4(2.0 \%)$ & \\
\hline Secondary education. & $24(12.0 \%)$ & $22(11.0 \%)$ & \\
\hline University. & $46(23.0 \%)$ & $44(22.0 \%)$ & \\
\hline Post-University. & $1(0.5 \%)$ & $3(1.5 \%)$ & \\
\hline -Occupation: & & & \multirow{3}{*}{0.644} \\
\hline House wife. & $148(74.0 \%)$ & $152(76.0 \%)$ & \\
\hline .Occupied. & $52 \quad(26.0 \%)$ & $48 \quad(24.0 \%)$ & \\
\hline --Residence: & & & \multirow{3}{*}{0.788} \\
\hline .Rural. & $166(83.0 \%)$ & $168(84.0 \%)$ & \\
\hline .Urban. & $34(17.0 \%)$ & $32(16.0 \%)$ & \\
\hline
\end{tabular}


Table(2):Obstetrical history of the studied women.

\begin{tabular}{|c|c|c|c|}
\hline Item & Intervention Group (200) & $\begin{array}{c}\text { Control Group } \\
(200)\end{array}$ & P-value \\
\hline \multicolumn{3}{|l|}{ Deliveries: } & \multirow{3}{*}{0.141} \\
\hline$-\quad 1-3$ & $124(62.0 \%)$ & $138(69.0 \%)$ & \\
\hline$-\quad>3$ & $76(38.0 \%)$ & $62(31.0 \%)$ & \\
\hline \multicolumn{3}{|l|}{ Abortions: } & \multirow{4}{*}{0.000} \\
\hline$-\quad$ None & $37(18.5 \%)$ & $41(20.5 \%)$ & \\
\hline $1-2$ & $56(28.0 \%)$ & $111(55.5 \%)$ & \\
\hline$>3$ & $107(53.5 \%)$ & $48(24.0 \%)$ & \\
\hline \multicolumn{3}{|l|}{ Mode of delivery: } & \multirow{3}{*}{0.480} \\
\hline .Vaginal. & $116(58.0 \%)$ & $109(54.5 \%)$ & \\
\hline C.s & $84(42.0 \%)$ & $91(45.5 \%)$ & \\
\hline \multicolumn{3}{|l|}{ History of contraceptive methods used before: } & \multirow{4}{*}{0.744} \\
\hline. Hormonal & $134(67.0 \%)$ & $127(63.5 \%)$ & \\
\hline . Non-Hormonal. & $32(16.0 \%)$ & $34(17.0 \%)$ & \\
\hline Not used before & $34(17.0 \%)$ & $39(19.5 \%)$ & \\
\hline Duration of Hormonal methods used & No. ( 134$)$ & No. (127) & \multirow{4}{*}{0.343} \\
\hline Less than one year & $24(17.9 \%)$ & $32(25.2 \%)$ & \\
\hline $.1-<5$ years & $97(72.4 \%)$ & $85(66.9 \%)$ & \\
\hline More than 5 years & $13(9.7 \%)$ & $10(7.9 \%)$ & \\
\hline
\end{tabular}

Table(3): Current Obstetrical and medical history of the studied women

\begin{tabular}{|c|c|c|c|}
\hline Items & $\begin{array}{l}\text { Intervention } \\
\text { Group (200) }\end{array}$ & $\begin{array}{c}\text { ControlGroup } \\
(\mathbf{2 0 0 )}\end{array}$ & $\begin{array}{c}\mathbf{P}- \\
\text { value }\end{array}$ \\
\hline \multicolumn{3}{|l|}{ Parity: } & \multirow[t]{4}{*}{0.348} \\
\hline Primi para & $42(21.0 \%)$ & $46(23.0 \%)$ & \\
\hline Multi para & $130(65.0 \%)$ & $117(58.5 \%)$ & \\
\hline Grand multipara & $28(14.0 \%)$ & $37(18.5 \%)$ & \\
\hline \multicolumn{4}{|l|}{$\begin{array}{l}\text { Medical conditions with } \\
\text { pregnancy: }\end{array}$} \\
\hline . None & $133(66.5 \%)$ & $128(64.0 \%)$ & 0.600 \\
\hline Hypertensive disorders & $18(9.0 \%)$ & $21(10.5 \%)$ & 0.613 \\
\hline $\begin{array}{l}\text { Haemorrhagic } \\
\text { disorders }\end{array}$ & $11 \quad(5.5 \%)$ & $14(7.0 \%)$ & 0.535 \\
\hline Diabetes Mellitus & $18(9.0 \%)$ & $16(8.0 \%)$ & 0.720 \\
\hline Renal diseases & $\begin{array}{ll}12(6.0 \%) \\
\end{array}$ & $14(7.0 \%)$ & 0.685 \\
\hline . Others & $\begin{array}{ll}8 & (4.0 \%) \\
\end{array}$ & $7(3.5 \%)$ & 0.792 \\
\hline \multicolumn{4}{|l|}{$\begin{array}{c}\text { Past thromboembolic } \\
\text { events: }\end{array}$} \\
\hline .Presence of events & $2(1.0 \%)$ & $3(1.5 \%)$ & 0.703 \\
\hline \multicolumn{4}{|l|}{$\begin{array}{c}\text { Type of } \\
\text { thromboembolic event: }\end{array}$} \\
\hline . DVT & $3(1.5 \%)$ & $4(2.0 \%)$ & 0.703 \\
\hline. $\mathrm{PE}$ & $0(0.0 \%)$ & $0(0.0 \%)$ & \\
\hline $\begin{array}{c}\text { Received thrombo- } \\
\text { prophylaxis treatment: }\end{array}$ & & & 0.653 \\
\hline Received & $27(13.5 \%)$ & $24 \quad(12.0 \%)$ & \\
\hline Not received & $173(86.5 \%)$ & $176(88.0 \%)$ & \\
\hline
\end{tabular}

Table(4): Distribution of the studied women according to the presence of VTE risk factors.

\begin{tabular}{|r|r|r|r|}
\hline Risk Factors & Intervention Group (200) & $\begin{array}{r}\text { Control Group } \\
\mathbf{( 2 0 0 )}\end{array}$ & $\begin{array}{r}\text { P-value } \\
\text {. Family history of VTE }\end{array} \quad 3(1.5 \%)$ \\
\hline . Previous attack of VTE & $3(1.5 \%)$ & $1.0 \%)$ & 0.653 \\
\hline Prolonged immobilization & $46(23.0 \%)$ & $41(20.5 \%)$ & 0.615 \\
\hline . High parity & $28(14.0 \%)$ & $37(18.5 \%)$ & 0.545 \\
\hline Age more than 35 years & $47(23.5 \%)$ & $39(19.5 \%)$ & 0.223 \\
\hline . Preeclampsia & $12(6.0 \%)$ & $14(7.0 \%)$ & 0.330 \\
\hline Ante partum hemorrhage & $5(2.5 \%)$ & $3(1.5 \%)$ & 0.685 \\
\hline . ART & $3(1.5 \%)$ & $7(3.5 \%)$ & 0.721 \\
\hline . Passive smoking & $29(14.5 \%)$ & $45(22.5 \%)$ & 0.200 \\
\hline Multiple pregnancy & $13(6.5 \%)$ & $17(8.5 \%)$ & 0.069 \\
\hline . Caesarean section & $84(42.0 \%)$ & $91(45.5 \%)$ & 0.448 \\
\hline . Diagnosed infection & $22(11.0 \%)$ & $18(9.0 \%)$ & 0.480 \\
\hline . Blood transfusion & $1(0.5 \%)$ & $2(1.0 \%)$ & 0.505 \\
\hline
\end{tabular}

More than one risk factor was present 
Table(5): The studied women's (intervention group) knowledge about venous thromboembolism: Closed ended questions (pre- post test)

\begin{tabular}{|c|c|c|c|c|}
\hline Item & Pre-test & $\begin{array}{l}\text { Intervention } \\
\text { Group (200). }\end{array}$ & $\begin{array}{r}\text { Post-test } \\
\text { Intervention } \\
\text { Group }(200)\end{array}$ & P-value \\
\hline \multicolumn{5}{|l|}{$\begin{array}{r}\text {-Which of the following might increase women's chances of } \\
\text { getting a DVT? }\end{array}$} \\
\hline .Immobility & & $56(28.0 \%)$ & $141(70.5 . \%)$ & $0.000^{*}$ \\
\hline .Obesity & & $76(38.0 \%)$ & $178(89.0 \%)$ & $0.000^{*}$ \\
\hline Trauma such as a broken leg & & $39(19.5 \%)$ & $141(70.5 . \%)$ & $0.000^{*}$ \\
\hline .Birth control pill & & $31(15.5 \%)$ & $179(89.5 \%)$ & $0.000^{*}$ \\
\hline .Pregnancy & & $67(33.5 \%)$ & $159(79.5 \%)$ & $0.000^{*}$ \\
\hline Surgery and pueriperium & & $48(24.0 \%)$ & $176(88.0 \%)$ & $0.000^{*}$ \\
\hline .Cesarean delivery & & $27(13.5 \%)$ & $169(84.5 \%)$ & $0.000^{*}$ \\
\hline .Previous attack of DVT & & $48(24.0 \%)$ & $182(91.0 \%)$ & $0.000^{*}$ \\
\hline .Don't know & & $124(62.0 \%)$ & $3(1.5 \%)$ & $0.000 *$ \\
\hline \multicolumn{5}{|l|}{-Which of the following are signs and symptoms of DVT? } \\
\hline . Swelling in one leg & & $34(17.0 \%)$ & $139(69.5 \%)$ & $0.000^{*}$ \\
\hline . Redness \& swelling in one leg & & $61(30.5 \%)$ & $158(79.0 \%)$ & $0.000^{*}$ \\
\hline . Calf pain in one leg & & $24(12.0 \%)$ & $129(64.5 \%)$ & $0.000^{*}$ \\
\hline Swelling in both legs & & $35(17.5 \%)$ & $158(79.0 \%)$ & $0.000^{*}$ \\
\hline Fever & & $41(20.5 \%)$ & $87(43.5 \%)$ & $0.000^{*}$ \\
\hline . Don't know & & $113(56.5 \%)$ & $2(1.0 \%)$ & $0.000^{*}$ \\
\hline \multicolumn{5}{|l|}{-Which of the following would help prevent a DVT? } \\
\hline Walking or stretching and moving the legs & & $31(15.5 \%)$ & $146(73.0 \%)$ & $0.000^{*}$ \\
\hline . Drinking plenty of fluids & & $43(21.5 \%)$ & $157(78.5 \%)$ & $0.000^{*}$ \\
\hline Eating lots of fibers & & $42(21.0 \%)$ & $141(70.5 . \%)$ & $0.000 *$ \\
\hline . Bed rest & & $24(12.0 \%)$ & $180(90.0 \%)$ & $0.000^{*}$ \\
\hline Washing and bathing regularly & & $27(13.5 \%)$ & $136(68.0 \%)$ & $0.000 *$ \\
\hline . Don't know & & $102(51.5 \%)$ & $0 \quad(0.0 \%)$ & $0.000^{*}$ \\
\hline \multicolumn{5}{|l|}{ - Which of the following are signs and symptoms of PE? } \\
\hline . Difficulty breathing & & $32(16.0 \%)$ & $117(58.5 \%)$ & $0.000^{*}$ \\
\hline Chest pain & & $28(14.0 \%)$ & $122 \quad(61.0 \%)$ & $0.000^{*}$ \\
\hline Coughing up blood & & $18(9.0 \%)$ & $147(73.5 \%)$ & $0.000^{*}$ \\
\hline . Rapid Breathing & & $6(3.0 \%)$ & $159 \quad(79.5 \%)$ & $0.000 *$ \\
\hline . Headache & & $6(3.0 \%)$ & $112(56.0 \%)$ & $0.000^{*}$ \\
\hline Sore throat & & $4(2.0 \%)$ & $98 \quad(49.0 \%)$ & $0.000^{*}$ \\
\hline . Don't know & & $161(80.5 \%)$ & $3 \quad(1.5 \%)$ & $0.000^{*}$ \\
\hline
\end{tabular}

More than one response allowed

Figure(2): The studied women knowledge about venous thromboembolism, $\mathrm{P}=0.000$.

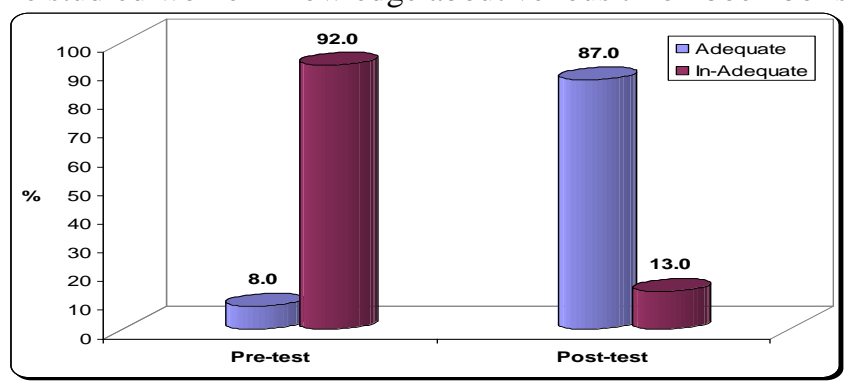

Table(6): How the studied women learned about VTE?

\begin{tabular}{|l|l|}
\hline Source: & Intervention Group(200). \\
\hline . Family member/friend & $19(9.5 \%)$ \\
\hline . TV / Newspaper & $16(8.0 \%)$ \\
\hline . Physician & $42(21.0 \%)$ \\
\hline . Nurse & $76(38.0 \%)$ \\
\hline . Pamphlet/ Poster & $34(17.0 \%)$ \\
\hline . Study & $3(1.5 \%)$ \\
\hline . Another patient & $1(0.5 \%)$ \\
\hline . Physiotherapist & $2(1.0 \%)$ \\
\hline . Pharmacist & $0(0.0 \%)$ \\
\hline
\end{tabular}

* More than one response allowed

Table (7): Incidence of new onset postpartum VTE among groups.

\begin{tabular}{|c|c|c|}
\hline & $\begin{array}{r}\text { Intervention Group (perform Leg exercise+ } \\
\text { following Ng instruction) }\end{array}$ & $\begin{array}{r}\text { Control Group } \\
\text { (not attending the Nursing program) } \\
(200)\end{array}$ \\
\hline
\end{tabular}


Effect of Educational Nursing program on reducing the incidence of Venous Thromboembolism

\begin{tabular}{|r|r|r|r|r|}
\hline & DVT & PE & DVT & PE \\
\hline $1^{\text {st }}$ week postpartum $(200)$ & $0(0.0 \%)$ & $0(0.0 \%)$ & $\mathbf{1}(0.5 \%)$ & $0(0.0 \%)$ \\
\hline Up to 6 $^{\text {th }}$ week postpartum & $\mathbf{1}(0.5 \%)$ & $0(0.0 \%)$ & $\mathbf{1}(0.5 \%)$ & $\mathbf{1}(0.5 \%)$ \\
\hline Up to 12 $2^{\text {th }}$ week postpartum & $0(0.0 \%)$ & $0(0.0 \%)$ & $0(0.0 \%)$ & $0(0.0 \%)$ \\
\hline Total & & $1(0.5 \%)$ & $3(1.5 \%)$ \\
\hline
\end{tabular}

Fig.3: VTE cases encountered among women in the 2 study groups $\mathrm{P}=0.000$.

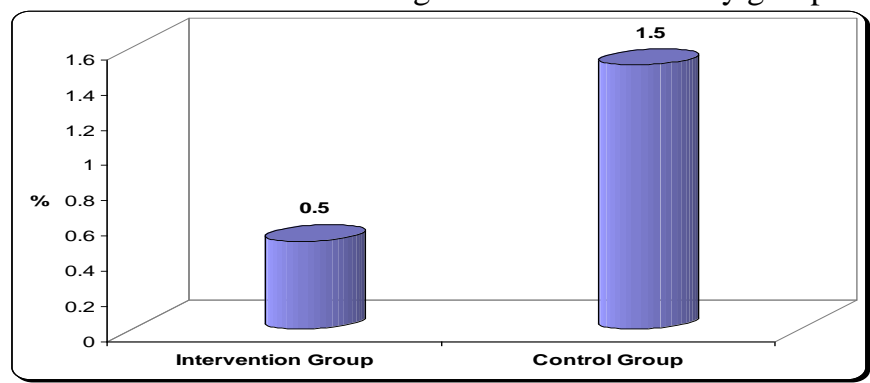

\section{References}

[1]. An Official American Thoracic Society/Society of Thoracic Radiology Clinical Practice Guideline-Evaluation of Suspected Pulmonary Embolism in Pregnancy. Am J Respir Crit Care Med. 2011 Nov 15;184(10):1200-8.

[2]. Alonso-Coello P, Ebrahim S, Guyatt GH, Tikknen K AO, Eckman MH, Neumann L, McDonald SD, Akl EA, and Bates S M(2012): Evaluating patient values and preferences for thromboprophylaxis decision making during pregnancy: a study protocol.

[3]. -Bates SM, Greer IA, Middeldorp S, Veenstra DL, Prabulos AM, and Vandvik PO.(2012): VTE, thrombophilia, antithrombotic therapy, and pregnancy. Chest;141(2 Suppl):e691S-e736S.

[4]. -Davis,P.(2004): DVT prevention...is it possible? Journal of Orthopedics Nursing 8 February : 58-59

[5]. -Dino W.R and Kenneth V.L.(2004): deep venous thrombosis and Pulmonary Embolisms: Part II. Treatment and Prevention American Faculty Physicians, vol.69. No. 12: 2841-2847.

[6]. Egyptian Demographic and Health Survey (2014): Ministry of Health and Population, National Population Council 2014.

[7]. -Elizabeth, Anderson.(2013): Venous Thromboembolism (Vte)In pregnancy, labour and post natal period-clinical guideline for the diagnosis, referral, treatment and ongoing management. Royal Crown wall Hospital ,Guideline for the diagnosis, referral, treatment and ongoing management. Version 1.1-Epi info ${ }^{\mathrm{TM}}$, CDC, USA,2008.-Goldhaber SZ.(2007): Venous thromboembolism risk among hospitalized patients: magnitude of the risk is staggering. Am J Hematol ;82:775-6.

[8]. -Greer I.A, (2012):, Faculty of Health and Life Sciences, University of Liverpool, Foundation Building, Liverpool L69 7ZX, United Kingdom Thrombosis in pregnancy: updates in diagnosis and management Hematology 2012 American Society of Hematology 213:217

[9]. -Hodgson L.,J and Emed J.,D(2007): Exploring nurses' experience with the implementation of the venous thromboembolism prophylaxis protocol. Unpublished master's thesis. Montreal, Quebec,Canada: McGill University;

[10]. -Iori A, Kearon C, Filippuci E, Marcucci M, Macura A, Pengo V, Siragusa S, Palareti G (2010): Risk of recurrence after a first episode of symptomatic venous thromboembolism provoked by a transient risk factor: a systematic review. Arch intern Med, 170:1710-1716

[11]. -Jacobsen AF, Skjeldestad FE, and Sandset PM(2008): Incidence and risk patterns of venous thromboembolism in pregnancy and puerperium:a register-based case-control study. Am J Obstet Gynecol.;198:233-234.

[12]. -Kearon C, Akl EA, and Comerota AJ(2012):. Antithrombotic therapy for VTE disease: antithrombotic therapy and prevention of thrombosis. American College of Chest Physicians evidencebased clinical practice guidelines. 9th Ed. Chest;141(2Suppl):e419Se494S.

[13]. -Kehl-Pruett, W(2006): Deep vein thrombosis in hospitalized patients: a review of evidence-based guidelines for prevention. DCCN;25:53-8.-Lewis G(2007): Saving Mothers' lives: Reviewing maternal deaths to make motherhood safer- 2003-2005. Confidential Enquiry into maternal and child Health: The sixth report of the confidential Enquiries into Maternal Death in the United Kingdom. London: RCOG Press.

[14]. -Milagros C., Ana M.F., Isabel R., and Loreto G., (2011): Post cesarean section thromboprophylaxis with two different regimens of Bemiparin, Obstetrics and Gynecology International, Vol.2011:548372.

[15]. -Morrison R. Venous thromboembolism(2006): scope of the problem and the nurse's role in risk assessment and prevention. J Vasc Nurs ;24:82-90. -Nelson-Piercy C, Powrie R, Borg JV, Rodger Talbot DJ,Stinson J and Greer IA.(2011): Tinzaparin use in pregnancy: an international, retrospective study of the safety and efficacy profile. Eur J Obstet Gynecol Reprod Biol.;159:293-299.

[16]. -Noble SIR, Nelson A, Turner C, et al.( 2006): Acceptability of low molecular weight heparin thromboprophylaxis for inpatients receiving palliative care: qualitative study. BMJ;332:577-80.

[17]. -Pomp ER, Lenselink AM, Rosendaal FR, et al.(2008): Pregnancy, the post partum period and prothrombotic defect:risk of venous thrombosis in the MEGA study. J Thromb Haemost; 6: 632-637.

[18]. -Sag LS, Marianne McGee, and Jessica DE(2008): Knowledge of Venous Thromboembolism prevention among hospitalized patients, Journal of Vascular Nursing Vol. 26, No. 4; 109-117.

[19]. -Samuel Z, Goldhaber, (2003 ):Deep- vein thrombosis: Advancing Awarness to protect patient lives. American Public Health Association . Public Health Leadership Conference on Deep- Vein Thrombosis Washington, D.C. February, 26.

[20]. -Simpson EL, Lawrenson RA, Nightingale AL, and Farmer RDnce (2001): Venous thromboembolism in pregnancy and the puerperium incidence from a London perinatal database BJOG;108:56-60.

[21]. -Tooher R, Gates S, Dowswell T, Davis LJ (2010): Prophylaxis for venous thromboembolic disease in pregnancy and the early postnatal period. In Cochrane Database of Systematic Reviews: doi:10.1002/14651858.CD001689.pub2. Issue 5. Art. No.: CD001689.

[22]. -Yaakobche, DzarrA.A, IsmailA.A, Nik Zky N(2010): Anticoagulant therapy for deep vein thrombosis (DVT) IN PREGNANCY. The Cochrane collaboration and published in the Cochrane library 2010, Issue 6. 